América sin Nombre, n.o 23 (2018): 211-220

DOI 10.14198/AMESN.2018.23.17

ISSN: 1577.3442 / eISSN: 1989-9831

Fecha de recepción: 21/03/2018

Fecha de aceptación: 25/04/2018
Modo de citación de este artículo:

Quezada Camberos, Silvia. «La identidad colectiva en tres cuentos latinoamericanos». Madurez de la joven poesía mexicana. Alejandro Higashi e Ignacio Ballester (coordinadores). América sin Nombre, 23 (2018): 211-220, DOI: 10.14198/AMESN.2018.23.17

Link para este artículo: http://dx.doi.org/10.14198/AMESN.2018.23.17

\title{
La identidad colectiva en tres cuentos latinoamericanos
}

\author{
The collective identity in three latin american tales
}

\author{
Silvia Quezada Camberos* \\ Universidad de Guadalajara (México)
}

\section{Resumen}

La identidad colectiva es una entidad relacional conformada por personas vinculadas entre sí, conectadas por un sentimiento común de pertenencia. El conjunto de individualidades comparte un núcleo de símbolos y representaciones sociales que los lleva a actuar en una misma dirección cuando se presentan problemas comunes (Valenzuela). Desde la psicología social, los actores en colectivo atribuyen significados específicos a los hechos con los cuales se enfrentan, así como a los sistemas de relaciones sociales en los que se insertan dichas acciones (Della Porta \& Diani). La identidad colectiva puede observarse cuando un conjunto de individualidades actúa hacia una misma dirección, convencida del bien común. Este artículo se acerca a tres cuentos latinoamericanos que comparten dicha temática: «Y vendimos la lluvia» de Carmen Naranjo; «Los trabajos de la ballena» de Eraclio Zepeda y «La vaca» de Carlos Changmarín con el objetivo de mostrar la representatividad de la identidad colectiva.

Palabras clave: narrativa latinoamericana, identidad colectiva, análisis sociocrítico, análisis comparativo, cuento hispanoamericano.

\begin{abstract}
The collective identity is a relational entity formed by a group of people linked together, and connected by a common feeling of belonging. The set of individualities shares a core of symbols and social representations that carries them to act as a group in the same direction, when a common problematic is presented (Valenzuela). From a social-psychology point of view, the actors of a collective group assign specific meanings to the facts that they face, as well as to the systems of social relations in which the actions are inserted (Della Porta $\&$ Dianai). The collective identity can be observed when a set of individualities moves to the same direction, convinced that is the common well. This article is an approach to three latin american short stories, which shares the same topic: «Y vendimos la lluvia» by Carmen Naranjo; «Los trabajos de la ballena» by Eraclio Zepeda and «La vaca» by Carlos Changmarín, with the main goal of displaying the representativeness of the collective identity.
\end{abstract}

Keywords: latin-american narrative, collective identity, socio-critical analysis, comparative analysis, hispanic-american short stories.

* Silvia Quezada Camberos (Guadalajara, 1957). Coordina la Maestría en Estudios de Literatura Mexicana de la Universidad de Guadalajara. Es doctora en Humanidades y Artes, pertenece al Seminario de Cultura Mexicana. 


\section{El corpus general de la investigación}

La lectura de 117 libros de cuentos panameños publicados en el siglo xx permitió la identificación de tópicos comunes trabajados por sus autores con la producción de escritores mexicanos. Se destacaron la identidad colectiva, el pensamiento mágico y el tratamiento del género, como la tríada con mayor número de trabajos. Autores como Pedro Rivera, Carlos Changmarín, Moravia Ochoa, Rosa Quirós y Justo Arroyo, encontraron intereses similares en Juan Rulfo, Eraclio Zepeda, Queta Navagómez, Elena Garro y Guillermo Sheridan, con narraciones donde la corrupción de la inocencia, el sentido compartido ante un problema común o la creencia de seres sobrenaturales muestran sus peculiaridades. A los temas similares se suman los modos del discurso, las formas de la retórica que embellecen las realidades más crudas, porque las anécdotas parecen rebasar los grados de la verosimilitud. Con un corpus narrativo panameńo-mexicano, el segundo reto fue localizar los mismos temas en la literatura costarricense, los cuales son revisados en este artículo. Por razones de espacio, el artículo considera únicamente al tópico de la identidad colectiva, como muestra de un trabajo más extenso.

El propósito de la comparación integral reside en cotejar cuentos costarricenses, mexicanos y panameńos seleccionados entre el conjunto de la producción narrativa del siglo Xx y XXI en dichos países. La elección surge de la coincidencia descubierta entre los cuentos rurales, los cuentos urbanos y los de temática de género localizada en la vida lectora de un equipo de trabajo trinacional. La selección es arbitraria, como toda antología. El objetivo es presentar un retablo literario, capaz de demostrar que los tópicos y las estéticas en Latinoamérica no se encuentran demasiado disímiles de las mismas preocupaciones.

En un contexto globalizado, la identidad colectiva une individualidades que parecieran a punto de sucumbir. El trabajo intenta observar los modos de la identidad colectiva ante problemas que afectan a todos los involucrados en una circunstancia por enfrentar. Se formula el estudio de la identidad colectiva en tres cuentos latinoamericanos, procedentes de Costa Rica, México y Panamá, textos que hasta ahora no han sido analizados desde esta perspectiva, y en el caso de los centroamericanos, muy poco estudiados desde dicho enfoque. Es un hecho que la literatura del centro del continente americano no ha logrado la difusión necesaria para ser conocida allende sus fronteras naturales. Esta acción quiere ser una contribución modesta a ese afán de reconocimiento hacia la literatura centroamericana.

Es pertinente aclarar que un acercamiento de esta naturaleza no debe contemplarse como un ejercicio de literatura comparada, puesto que dicho método exige el estudio de dos o más literaturas en lengua diversa. Por lo tanto, el enfoque de la investigación asienta su base en el análisis comparativo de cuentos escritos en español, atendiendo al tópico tratado y las formas literarias de abordarlo.

La premisa de que las literaturas latinoamericanas, hijas del colonialismo, se nutrieron de la tradición europea, ahora han alcanzado otras cimas, muestran herramientas técnicas similares, propias de la retórica occidental. El método empleado es el del análisis comparativo, aunado a la teoría sociocrítica de Claude Duchet.

Para llevar a cabo la exégesis fue necesario acercarse a los estudios relativos al cuento en Panamá, los cuales comienzan a partir de 1950, con libros como El cuento en Panamá, de Rodrigo Miró, los cuales fueron continuados de forma fragmentaria por algunos estudiosos, entre los que destaca la académica Margarita Vásquez, quien presenta en 2004, El cuento en Panamá (1950-2003). (Abundancia de peces).

En México, los cuentistas del Centro Mexicano de Escritores comenzaron a publicar por esta misma década de los cincuenta sus primeros trabajos, casos precisos de Juan Rulfo, con El llano en Llamas y Pedro Páramo, y en el caso de Carlos Fuentes, la colección titulada Los días enmascarados; libros que muestran, en el caso de los dos primeros, el mundo rural, pero también el ambiente urbano, en el caso del tercero.

El cuento costarricense, menos conocido que los anteriores, encuentra expresión plena a partir de 1890, con autores como Aquileo J. Echeverría, Manuel González Zeledón, y Rafaela Contreras. Los primeros estudios que trascendieron frontera fueron hechos por Seymour Menton en 1964 (El cuento costarricense) y Sergio Ramírez en 1973 con dos tomos de una Antología del relato costarricense, empresa a la que se sumó Jézer González con la Antología del relato costarricense, entre otros esfuerzos. Baste este somero repaso para entrar en materia.

Para cerrar este apartado, sin embargo, es necesario aclarar que la definición de cuento seguida es la consignada por Claude Brémond: "Variedad del relato, un discurso que integra una sucesión de eventos de interés humano en la unidad de una misma acción» (citado en Beristáin 126). 


\section{Contextos identitarios}

La escritora María Luisa Puga escribió a finales del siglo xx una novela que narra la historia de un adolescente fugitivo, quien huye de su pueblo cuando los portugueses llegan a colonizar la población. El joven africano no quiere abandonar sus creencias, sus rituales, ni su tradición. Se fuga en el primer barco, zarpa hacia la aventura. Luego de varios conflictos en el mar, vuelve a tocar tierra firme, y resuelve, junto con sus compañeros de aventura, fundar un asentamiento. Antes de decidir el sitio exacto de la fundación, el grupo lanza las preguntas siguientes: ¿Cuántos somos? ¿Qué vamos a decirles a nuestros hijos cuando nazcan? ¿Qué historia les vamos a heredar? ¿Quiénes son nuestros dioses? ¿Cuáles son nuestras costumbres? ¿Qué hacemos con los muertos? (Puga). Las respuestas a estas interrogantes conforman sin lugar a dudas, la génesis social de un acuerdo común en las formas de organizar la vida y la muerte.

De modo parecido, los tres cuentos del análisis comparado: «Y vendimos la lluvia» (Costa Rica 1989) de Carmen Naranjo ${ }^{1}$; "Los trabajos de la ballena" (México 1959) de Eraclio Zepeda ${ }^{2}$; y "La vaca» (Panamá 1959) de Carlos Changmarín ${ }^{3}$ encuentran

1. Carmen Naranjo fue una prolífica escritora costarricense, nació en 1928 y falleció en el 2012. Cultivó los géneros de la narrativa, la poesía, la dramaturgia y el ensayo. Su actividad política destacó por las labores a favor de la inserción de las mujeres costarricenses en la sociedad. Desempeñó también diversos cargos públicos (Ministra de Cultura, Directora del Museo Nacional y el Museo de Arte Costarricense, entro otros puestos públicos. Albino Chacón escribe «De manera general, la crítica la considera una de las principales renovadoras y modernizadoras de la narrativa costarricense, tanto en el orden de los temas tratados como por las técnicas narrativas utilizadas» (Chacón 321). Fue premiada en Chile, Guatemala, Venezuela y Costa Rica.

2. Nacido en el año 1937 Eraclio Zepeda fue militante del Partido Comunista Mexicano. Su producción artística destacó en poesía, narrativa y teatro. Recibió distinciones como la Medalla Conmemorativa del Instituto Nacional Indigenista (1980) y la Medalla Belisario Domínguez (2014). Fue Premio Xavier Villaurrutia (1982) y también Premio Nacional de Ciencias y Artes en el área de Lingüística y Literatura otorgado por la Secretaría de Educación Pública (2014). Recibió el título Doctor Honoris Causa por la Universidad de Ciencias y Artes de Chiapas y la Universidad Intercultural de Chiapas (2015). Falleció en el 2015.

3. «Una decidida convicción política y social de izquierda le ha deparado la cárcel y el destierro, pues Changmarín no ha callado su voz ni su actuación -especialmente entre el su afinidad en que los tres abordan el modo como un colectivo se enfrenta con un problema común estableciendo acuerdos surgidos de la tradición.

En "Los trabajos de la ballena» un abuelo marinero pesca al gran animal, y convoca a su familia a destazarlo. Toda la familia directa y política emprende la acción, aunque pronto la marea de moscas, las bandadas de pelícanos, alcatraces, gaviotas y zopilotes vuelven imposible la tarea. El esfuerzo colectivo no puede completarse, la carne se pudre, apesta. Para confrontar el problema la familia concilia un plan. Consulta al abuelo, quien toma una decisión salomónica: si no puede sacarse a la ballena del pueblo, habrá que sacar al pueblo de la ballena.

En «La vaca», un cuadrúpedo interrumpe la paz de la montańa panameña cuando asciende a un risco imposible, tan de difícil acceso, que ni siquiera las tropas invasoras habían logrado escalarlo para implantar su bandera. Los viejos se llenan de temor, de incompetencia, se cruzan de brazos, pero los jóvenes deciden intervenir, ellos no guardan aquellas ideas mágicas ni religiosas contrapuestas al espíritu de sentido común. Hay que devolver la vaca a tierra firme, impedir que siga quitando el sueño y la tranquilidad comunal, tan afectada por la vaca fugitiva. El problema se resuelve, aunque la res termina lastimada.

En «Y vendimos la lluvia» la situación económica apremiante de una nación endeudada con préstamos, lleva a sus autoridades a vender la lluvia a un país del Medio Oriente. Lo que inicialmente se concibió como un período de bonanza económica se convierte luego en mayores deudas con las instituciones financieras internacionales, una sequía producto de la carencia de agua y la consecuente inmigración del pueblo -en su totali$\mathrm{dad}-\mathrm{a}$ la nación árabe. El problema no se resuelve, al contrario, se dificulta aún más; el pueblo es visiblemente el más afectado.

Las tres narraciones del siglo $\mathrm{xx}$ fueron trabajadas para descubrir en ellas coincidencias y disidencias. "La vaca» pertenece al libro Faragual (1959) de Carlos Changmarín, el cual puede consultarse completo en línea de modo facsimilar; "Los trabajos de la ballena» forma parte de Asalto Nocturno (1959) de Eraclio Zepeda, y en el caso de "Y vendimos la

campesinado- ante la injusticia social» (Chacón 106). Carlos Changmarín (su seudónimo es la unión de sus apellidos paterno y materno) nació en Los Leones, Veraguas en Panamá en 1922 y falleció en el 2013. Cultivó la poesía y la narrativa. 
lluvia» se encuentra compilado en Otro rumbo para la rumba (1989) de Carmen Naranjo.

Para el método sociocrítico es importante el conocimiento del contexto previo de cada una de las narraciones, así como el inicio formal del texto, en el cual se reconocen el espacio, el tiempo y la identidad del relato; en un segundo momento se identifican los discursos sociales de los personajes, así como sus relaciones entre sí, lo que es conocido como sociograma; al final se inquieren las configuraciones sociológicas, entre las que se encuentran: el clima de la ideología y las ideologías de referencia.

Junto con el análisis sociocrítico, se trabaja el método de análisis literario, con fundamento en la comparación. No se trata de establecer paralelos entre las literaturas nacionales, sino que se busca confrontar los elementos que forman parte de las historias literarias traídas a la página. La pregunta de investigación sustantiva es: ¿Cómo resuelve un colectivo humano un problema común? Seguida de las dos preguntas siguientes: ¿Qué papeles juegan la tradición y el pensamiento religioso para resolver esos problemas? De estas analogías temáticas, construcciones paralelas y resoluciones diversas, se nutre el estudioso del análisis comparativo.

\section{Resultados y discusión}

En el cuento "La vaca» hay en el incipit una constitución discursiva que marca un antes y un después cuyo umbral traspasa la vaca como personaje. En las primeras páginas es evidente el uso por parte del narrador omnisciente de la conjugación verbal en pretérito imperfecto del modo indicativo (terminaba, ascendía, habían podido para mencionar algunos) cuya unidad se rompe con el sexto párrafo: «La vaca fue trepando» (Changmarín 20) y luego retomar el hilo narrativo con las acciones en el anterior tiempo verbal. Resulta significativo que quien rompe con la unidad pueblo-roca-temporalidad no haya sido un habitante, sino que en su lugar fuera un animal a quien el castigo divino no puede alcanzar: "Seguía, como un animal puede hacerlo, sin temor a duendes ni a viejos indios» (20).

Con el ascenso la vaca, desde la singularidad que representa, domina el espacio y a la totalidad del pueblo que ahora se halla ante sí: «Observaba las casitas, como pequeños dados sobre un mantel amarillento» (20) logrando lo que deseaba: disfrutar de un mejor pasto. El paso del tiempo marca no solo el mes en el que la vaca sube a la roca (marzo) sino que lleva a la mañana en que es avistada por un muchacho: «El día se hizo claro» (21). El espacio además traza una división entre el mundo humano (situado abajo) y el mundo animal arriba, [en]: «una piedra enorme, redonda como una totuma de diez metros de diámetro» (20).

La inserción de la identidad colectiva se concreta con la comunicación del muchacho a su madre sobre la vaca subida en la roca; la madre: «llamó a la comadre; la comadre enteró a la vecina, y así se supo la noticia» (21). Ahora con este hecho se abre el espacio de los personajes: son los hombres que han regresado de sus trabajos en el campo, los ciudadanos mayores y la juventud. No es casual que quien comunica la noticia sea un muchacho y que otro secunde a los jóvenes a subir por el rescate. Con lo anterior, cada personaje que no está enfocado desde la individualidad, desempeña una función específica dentro del relato, como se muestra a continuación:

\begin{tabular}{|c|c|}
\hline Personajes & Funciones \\
\hline La vaca & $\begin{array}{c}\text { Objeto de atención, objeto } \\
\text { del problema }\end{array}$ \\
\hline Las mujeres & $\begin{array}{c}\text { Comunican la situación } \\
\text { problemática }\end{array}$ \\
\hline Los ciudadanos mayores & $\begin{array}{c}\text { Obstaculizan con sus } \\
\text { creencias la solución al } \\
\text { problema }\end{array}$ \\
\hline Los hombres & $\begin{array}{c}\text { No enfrentaron el problema } \\
\text { por la tradición de no subir a } \\
\text { la roca. }\end{array}$ \\
\hline Los jóvenes & $\begin{array}{c}\text { Uno de ellos (el muchacho) } \\
\text { avista el problema, la } \\
\text { colectividad lo soluciona. }\end{array}$ \\
\hline
\end{tabular}

Tabla 1. Funciones de los personajes. Elaboración propia.

«La vaca» de Carlos Changmarín posee un final cerrado en el que la comunidad soluciona el problema:

La vaca ciega y muda, que ahora anda por allí rumiando el verdor de las huertas, jamás ha querido poner, de nuevo, sus patas en las alturas y deambula sin más ni más que la realidad de sus ojos rotos para siempre, pero como una bandera viviente, de los arrojados corazones (27-28).

Se compara al cuadrúpedo cual símbolo vivo frente al que no pudieron colocar los estadounidenses en la roca para ser resguardado desde la memoria colectiva: «Los muchachos nunca se cansaron de contar la 
historia de la vaca» (27). En suma, este texto sobrio refiere con pocos datos una soberanía en la figura de la vaca de la nación panameña ${ }^{4}$ y el resguardo colectivo e identitario.

El eje espacio-tiempo asimismo se hace presente en las primeras líneas del cuento de Eraclio Zepeda "Los trabajos de la ballena" porque en la voz del narrador (un muchacho abandonado por su madre) se descubren claves de los acontecimientos narrados en un lenguaje llano: «Este puerto que usted ve con su muelle de concreto [...], es ahora un puerto bueno» (110) y con lo cual se dirige a un interlocutor: "Porque en este puerto, amigo" (110) estableciendo ya en el incipt una armazón narrativa que el lector completará hasta las últimas líneas del cuento.

La ballena rompe la apacibilidad del pueblo compuesto por un círculo familiar con tres casas de habitación. Establece un antes y un después con la movilización de los pobladores a otro sector de la costa pesquera: «Fue un martes en la tarde cuando mi santo abuelo pescó la ballena» (113) y con la siguiente actividad colectiva que representó destazar ese animal con herramientas rudimentarias: «Todo el pueblo estuvo tirando las cuerdas hasta el atardecer de aquel jueves bendito [...] Al amanecer empezamos a destazarla» (113-114).

Acá al igual que en la revisión del cuento anterior se distinguen los personajes también dentro del anonimato y con claras funciones en el mundo narrado:

\begin{tabular}{|c|c|}
\hline Personajes & Funciones \\
\hline La ballena & $\begin{array}{c}\text { Objeto de remolque, objeto } \\
\text { del problema }\end{array}$ \\
\hline El abuelo & $\begin{array}{c}\text { Lleva el problema al pueblo/ } \\
\text { Saca al pueblo del problema }\end{array}$ \\
\hline El pueblo & $\begin{array}{c}\text { Destaza al problema/Se } \\
\text { traslada de sitio evitando el } \\
\text { problema. }\end{array}$ \\
\hline
\end{tabular}

Tabla 2. Funciones de los personajes. Elaboración propia.

Si con la gesta de los jóvenes se resuelve el hecho angustioso de la vaca en el cuento de Carlos

4. «La vaca» observa a Panamá como nación tratada en el desarrollo textual y aborda las incursiones estadounidenses en la región, pero lo hace desde el juego irónico que fue la vaca quien sí logró escalar tan escabroso peñasco «[...] se dijo, que nadie había subido hasta allá; que los norteamericanos anduvieron clavando señales por los picos más altos del Istmo, para sus bases militares, pero que no habían podido colocar una bandera suya en la peña del cerro» (19).
Changmarín pese al temor colectivo de los ancianos y la pasividad de los adultos, es entonces que en este otro texto se muestra al causante del problema como al abuelo aunque también lo resuelve. El orgullo de llevar un cetáceo a sus nietos que no habían visto ninguno: "Y nosotros que no habíamos visto una ballena no podíamos creer nada» (112) hizo que el anciano rompiera las leyes de la naturaleza después de días de no pescar nada "Y pasando la mano una y otra vez sobre la herida, entendió que el animal estaba muerto desde antes, en pago de Dios sabe qué mala ventura» (113).

«Los trabajos de la ballena» cierra con diversos elementos que llevan al clímax narrativo; hay empleo de suspenso por parte del abuelo y utilización de una alegoría que pretende adelantar un hecho que no puede evadirse y es que la comunidad vivirá mejor con un futuro boyante en otro sector de la costa ${ }^{5}$ como se muestra respectivamente en las siguientes citas:

- ¿Y ahora qué vamos a hacer?

Y el abuelo no contestó hasta que aplastó bien una hormiga con el dedo gordo del pie derecho:

-Si no podemos sacar la ballena del pueblo, pues saquemos al pueblo de la ballena.

$Y$ entonces nos venimos a hacer el pueblo a esta Caleta de San Ramón ${ }^{6}$ (115).

Ese puerto que usted ve con su muelle de concreto, con su calle para ir y venir desde el principio al fin del caserío, con sus casas de ladrillo del lado de la tierra que es donde viven los pescadores y las barracas de madera junto al mar, en la playa, donde se sirve la comida a los fuereńos (110).

Carmen Naranjo anunciaba con un tono irónico un presagio que parece oscurecer este siglo y es la carencia de agua potable, "Y vendimos la lluvia» parte de

5. El narrador en «Los trabajos de la ballena» no difunde pistas para reconocer si el texto es de un punto geográfico preciso más que el dato de la Caleta de San Simón como sí sucede en "La vaca» de Carlos Changmarín y en el cuento de Carmen Naranjo "Y vendimos la lluvia».

6. Nótese en esta cita una inquietud plural que implica un problema colectivo, le sigue una acción individual (el abuelo aplasta la hormiga), el enlace con la conjunción "y» para expresar un sabio consejo y remata de nuevo con el enlace y la acción colectiva. Son expresiones desde la oralidad y desde el rescate de la memoria que le permite al narrador ser el portavoz del traslado del pueblo. 
que este recurso irrenovable puede venderse como se hace con cualquier producto comercial de consumo. El incipt anuncia ya en la primera línea una situación económica que no termina de resolverse al final del relato: «QQué jodida está la cosa!» (111), frase pronunciada por el ministro de hacienda y da paso a situaciones para que el lector comprenda el tono de la oración y la gravedad del asunto:

Su asesor agregó que no había un centavo en caja, la cola de las divisas le daba cuatro vueltas al perímetro de la ciudad, el Fondo tercamente estaba afirmando no más préstamos hasta que paguen intereses, recorten el gasto público, congelen los salarios, aumenten los productos básicos y disminuyan las tasas de importación, además quiten tanto subsidio y las instituciones de beneficios sociales (111).

Con esta cita se denota el tono imperativo de las medidas que deberá tomar la nación tropical lluviosa con el fin de disminuir el colapso económico y de donde se sigue que el: "pobre pueblo» (111) es quien ve deteriorada su calidad de vida: "[...] ya ni frijoles podemos comprar, ya nos tienen a hojas de rábano, a plátanos y a basura, aumentan el agua y el agua no llega a la casa a pesar de que llueve diariamente» (111). Acá hace su aparición otro objeto del problema que en contraste con los dos cuentos anteriormente analizados no será un animal quien lleva la situación enigmática a la comunidad.

El desarrollo del incipit trae consigo una interrogante que estructura el resto del texto en función de buscar una respuesta inmediata: «¿Es que a nadie se le ocurre en este país alguna pinche idea que solucione tanto problema?» (111) expresaba el presidente. Lo que sigue muestra una serie de párrafos-cuatro- constatando la profundidad de la situación: el cuadro de la clase política que no ofrece soluciones «[...] el gabinete en pleno pidió a gritos que iluminara un mejor porvenir[...]» (112); la pobreza galopante de la población que se compara con la de la clase poderosa a quien no toca las vacas flacas «El hambre y la pobreza ya no se podían esconder: gente sin casa, sin un centavo en el bolsillo [...]» (112); el papel de los medios de comunicación: «todas están inundadas, lo mismo que los periódicos y las radioemisoras, un pueblo sin noticias es un pueblo perdido» (113). No es sino hasta los últimos renglones del párrafo cuatro que se lee: «Si se pudiera exportar la lluvia, pensó el ministro» (113) como inquietud que flota y no halla asidero hasta líneas más abajo.
Resulta interesante que el hilo narrativo nos lleva de nuevo al despliegue de disposiciones en donde aparece el presidente, los medios de comunicación y la memoria colectiva como mecanismo que borraba las imágenes de la clase política: «La verdad es que el gobierno se había desteñido en la memoria del pueblo» (114). Esta disposición le toma al narrador dos párrafos más hasta que se da un giro revelado en tono impersonal ( $Y$ la solución salió de lo que menos se esperaba. El país organizó el concurso tercermundista de la Seńorita Subdesarrollo», 114). En este punto la historia se reescribe desde la óptica de lo que se avecina como un dominó de experiencias que está a punto de vivir la nación para salir del dilema.

Con la banalidad del concurso de belleza surge una figura femenina (representante del Emirato de los Emires ${ }^{7}$ ), ella lleva la noticia de que en la nación abunda el agua y la lluvia, elementos de los que carecen en el Medio Oriente. Su padre (Sultán Abun dal Tol) decidido llama al país y le propone al ministro de exportaciones la construcción de un acueducto para hacer llegar el preciado líquido al Emirato de los Emires.

La suerte que se esperaría de un intercambio comercial relativamente justo duró poco: «El pueblo sonrió, un poco menos de lluvia agradaba a todos, además se evitaban las siete vacas gordas, un

7. No es sino hasta que entran en el plano narrativo los personajes del Emirato de los Emires que se denota el uso de dos elementos significativos para la comprensión y valoración de la colectividad afectada por la crisis económica: el uso de letras mayúsculas para designar espacios geográficos y los nombres de los personajes. Así también destacan, dentro del discurso narrado, piezas que revelan aspectos lingüísticos y semánticos propios de la idiosincrasia costarricense y que de paso indican que la acción se desarrolla en Costa Rica con tintes urbanos (al contrario de los cuentos de Carlos Changmarín y de Eraclio Zepeda). La anotación de espacios como «[...] el parque central, en el parque nacional, en la plaza de la cultura, en la avenida central y en la avenida segunda» (112) refieren sitios de la capital costarricense; «El Seguro Social» (112) a la institución del Estado que vela por la salud pública llamada Caja Costarricense del Seguro Social fruto de las Garantías Sociales en el año 1941; el uso de giros, frases y juegos de palabras de tradición coloquial costarricense se cuelan en el texto brindándole un tono popular y por lo tanto, colectivo, se reconocen acá «iQué jodida está la cosa!» (111), «[... la gente los distinguía con el de aquél que se cree la mamá de tarzán y usa anteojos [...]» (114), «Ganó por unanimidad, reina absoluta del subdesarrollo, lo merecía, por cierto, no le faltaban colmillos ni muelas» (115). 
tanto pesadas» (116) para dar paso a acciones como la construcción de los acueductos que redujeron considerablemente el líquido: «El primer embudo se colocó en el Atlántico [...] Era necesario un poco más de esfuerzo. Se puso un embudo en el norte y otro en el sur" (117); las siete vacas gordas metáfora del dinero recibido por la venta de la lluvia: "Además de las tales vacas no se tenía seguridad alguna de que fueran gordas» (116), y por consiguiente, efectos no esperados tales como la sequía "Ambas zonas muy pronto quedaron como una pasa» (117) y la mano poderosa de los entes financieros internacionales que barrieron con el capital obtenido en la transacción: «No llegaban los cheques, ¿qué pasa? el Fondo los embargó para pagarse los intereses» (117).

"Y vendimos la lluvia» no cierra un trato positivo para la colectividad. Un individuo emigra al Emirato de los Emires (se trastoca el espacio y la identidad), los únicos que quedan en la nación son las autoridades porque el pueblo entero se moviliza al Oriente Medio: «La población disminuyó considerablemente, un buen día no amaneció nadie, con excepción del presidente y su gabinete» (118).

Tanto en "La vaca» como en "Los trabajos de la ballena» la colectividad de los adultos mayores sugiere particularidades; en el primero de ellos es objetora del rescate del cuadrúpedo mientras que en el cuento de Eraclio Zepeda es generadora pero a la vez facilitadora por la sabiduría. Está ausente tanto una como la otra en el cuento de Carmen Naranjo ya que las decisiones están en manos de las autoridades políticas de turno; lo que sí es rescatable es la movilización geográfica en los tres textos de grupos humanos como los jóvenes en "La vaca» y las poblaciones -en su totalidad- en "Y vendimos la lluvia» como en "Los trabajos de la ballena».

$\mathrm{El}$ caso es que, a pesar de quienes se opongan o no a la solución de los problemas que aquejan a las colectividades retratadas en los textos, las acciones son las que cuentan más que los beneficios obtenidos; es decir, en "La vaca» se logra rescatar un animal casi moribundo: «La muerte se iba. Era más fuerte el poder de los jóvenes campesinos, el profundo sentido de la humanidad de sus corazones» (27) y en "Los trabajos de la ballena» se aprovechó parte de esta a pesar del redoblado esfuerzo colectivo: "Y la carne que habíamos logrado aprovechar era menos de la mitad de la que aún tenía cubriéndole los huesos» (114). En el cuento de Carmen Naranjo hubo atisbos de una salud económica que duró poco: «Llegó el primer pago del Emirato de los Emires, ¡en dólares!, se celebró con una semana de vacaciones! (117).

Fruto del colonialismo español en los cuentos de Carmen Naranjo, Carlos Changmarín y Eraclio Zepeda se evidencia un sentido religioso que aunado a la tradición popular parece matizar de misticismo los textos. A propósito de la influencia de tradición judeocristiana heredada de los españoles pueden leerse los siguientes ejemplos: «Se hablaba de duendes, o de antiguos indios que moraban en sus alturas y por lo tanto, los campesinos sentían temor de trepar tan alto» («La vaca», 19); «Una mañana como siempre, mi santo abuelo se santiguó en las aguas y se fue al horizonte» («Los trabajos de la ballena», 112) y finalmente, en "Y vendimos la lluvia» con el caso de la figura religiosa de la Patrona de Costa Rica ${ }^{8}$ : «Alguien le propuso rezar y pedir a La Negrita, lo hizo y nada. Alguien le propuso restituir a la Virgen de Ujarrás» (112).

Destaca la identidad latinoamericana manifiesta en rasgos como los títulos de los cuentos, el uso de la música popular y el empleo del humor e ironía. Para este último aspecto, en los tres cuentos analizados, existe esa: «cualidad consistente en descubrir o mostrar lo que hay de cómico o ridículo en las cosas o en las personas, con o sin malevolencias" (Moliner 1587). En «Los trabajos de la ballena» la barca del abuelo no produce ruido porque: " no es como hoy en estas barcas que a punta de gasolina andan pedorréandose en las olas» (111) y en el cuento de Carlos Changmarín «[la vaca] echaba a un lado la nuca, "jondeaba" una chistosa mirada al valle» (20). Mención aparte merece " $\mathrm{Y}$ vendimos lluvia» porque más que humor se evidencia la ironía como recurso narrativo: "ya usted sabe de flaquitas, oscuritas, encogidas de hombros, piernas cortas, medio calvas, sonrisas cariadas, con ameba y otras calamidades» (114-115).

8. La Virgen de los Ángeles es la Patrona de Costa Rica desde 1824 en sustitución, por autoridades oficiales eclesiásticas, de la Virgen de Ujarrás; la primera figura femenina apareció en la provincia de Cartago (primera capital de la nación costarricense) durante la época colonial mientras que la Virgen de Ujarrás -aunque no hay datos oficiales- fue un obsequio del rey Felipe II de España a un fraile que llegó a las tierras de Costa Rica en el siglo xvi. Es de resaltar que los rezos por parte de las autoridades políticas para pedir una respuesta al problema se agotan en la primera virgen (Nuestra Seńora de los Ángeles) y por extensión, se traslada a la que fue dejada en el olvido colectivo (Nuestra Señora del Rescate o Virgen de Ujarrás). 
La oralidad se manifiesta en la sencillez de los títulos, "La vaca» conlleva el elemento simbólico de la soberanía popular pero a la vez denota la vida de campo con su agricultura y ganadería mientras que en el texto de Eraclio Zepeda los trabajos que generó el cetáceo le permitieron a un grupo consanguíneo mejorar de condición con su traslado a otro espacio. Carmen Naranjo apuesta por la enumeración con la frase: "y vendimos la lluvia» después de una serie de productos autóctonos: «habíamos vendido muy mal el atún, los delfines y el domo térmico, también los bosques y los tesoros indígenas» (117) que se fueron perdiendo de una nación que no logra levantarse de la decadencia económica. Se rescata, asimismo, que todos los cuentos poseen un lenguaje llano.

La música, aunada a la identidad colectiva, hace su aparición en dos de los cuentos ( $\mathrm{Y}$ vendimos la lluvia» $\mathrm{y}$ «Los trabajos de la ballena»); en este último el abuelo canta una canción popular que se llama La bella Lola9: "Cuando en la playa mi bella Lola/su larga cola luciendo va/los marineros se vuelven locos/ y hasta el piloto pierde el compás» (111). Ejemplos como estos: «Llegó julio y una tarde un ministro sin cartera y sin paraguas vio llover, vio gente $\operatorname{correr}^{10}{ }^{\text {» }}$ (113), «[...] le gustó incluso lo de un tal Leonardo Fabio $^{11}$ en eso de llovía y llovía» (115) aumentan el tono y la intensidad que el narrador desea mostrar con la lluvia. Son intertextualidades que apelan a la cotidianidad.

La mención de los personajes femeninos representa un último acercamiento develando con ello la cultura patriarcal que subyace como parte de la identidad latinoamericana. En lo que concierne a «Los trabajos de la ballena» las imágenes femeninas -que no ocupan funciones en la narración- se presentan por contraste; es decir, el narrador visiblemente juzga la acción de su madre desde su focalización como no santa: «y la de mi madre, que no resultó tan santa porque terminó perdiéndose con

9. Se desconoce el origen tanto de la letra como de la música de la canción que se reconoce como parte del canto de los marineros en la cinta La bella Lola (1962) protagonizada por la actriz española Sarita Montiel.

10. Armando Manzanero (compositor mexicano y cantante, 1935) escribió Esta tarde vi llover que forma parte del álbum A mi amor con amor (1967).

11. Leonardo Favio (1938-2012) cantante de origen argentino protagonizó Simplemente una rosa en el año 1971, de la cinta se derivó la canción con el mismo nombre que expresa una situación amorosa acentuada por el coro con el estribillo «Y llovía y llovía [...]». un marinero que un día asomó desnudo piloteando una barca de naufragio» (110) en contraposición con la de Santa Bárbara ${ }^{12}$ a quien su abuelo reza para que lo ayude en el trance del acarreo de la ballena. Son las dos únicas escenas con presencia femenina. Las mujeres en "La vaca» aunque no lo deseara el narrador son figuras de cotilleo que encadenan la noticia de la vaca sobre la colina. Solo son rescatables las muchachas: «Los jóvenes consiguieron coas, machetes, vasijas y escopetas. Detrás seguían alegremente los chiquillos, y luego las muchachas. Empezaron a escalar rápidamente las colinas. Ganaron la meseta. Se apresuraban» (26). Por último, en "Y vendimos la lluvia» subyacen tres imágenes de las mujeres; la primera de ellas ya tratada líneas arriba es la que connotan las vírgenes a quienes se les reza para pedir un milagro; la segunda corresponde a las jóvenes del concurso de belleza en cuyo tono narrativo se reconoce un aire despectivo; la tercera corresponde a la ganadora del concurso como comunicadora de la feliz noticia sobre el agua que abunda en la nación tropical.

Finalmente, este análisis merece reconocer que los tres escritores fueron ciudadanos destacados de sus naciones y no solo por el tono literario, sino por su trayectoria política; Carlos Changmarín al igual que Eraclio Zepeda militó en el Partido Comunista y su activismo lo llevó a colocarse del lado del pueblo en defensa de los derechos y la soberanía de la nación panameña. Eraclio Zepeda al igual que Carmen Naranjo ocupó puestos administrativos importantes y fue corresponsal del Partido Comunista Mexicano en Moscú. No es de extrañar que en los textos se evidencie un sentido social de problematización y lucha social en las figuras del pueblo campesino de "La vaca», en el pueblo costero de "Los trabajos de la ballena» y en la ciudadanía urbana retratada en «Y vendimos la lluvia». Son elocuentes, claros y directos los diálogos desde un narrador que se coloca al lado de la colectividad porque proviene de ella, así como una ausencia tanto en la mención de nombres como en los espacios, con la clara excepción del texto de Carmen Naranjo.

En el sentido de anonimato que se traduce como parte de la colectividad y la identidad cada personaje es reconocido más por sus ideas y acciones que por

12. Santa Bárbara data del siglo III aunque su nacimiento no se encuentra del todo claro. El acto de ruego del abuelo en el texto «Los trabajos de la ballena» es particular porque la santa es patrona de los militares y los mineros mayormente. 
sus nombres otorgándole con ello a los relatos un matiz de proletariado, de unidad en la lucha y en la resolución de conflictos. Se reconoce que, aunque se hicieron esfuerzos colectivos para la obtención de un bien común, este no cristalizó como se pensó en un inicio: en el texto de Carlos Changmarín los jóvenes rescataron una vaca afectada por la violencia de las aves de rapiña mientras que en " $\mathrm{Y}$ vendimos la lluvia» la situación económica se solucionó provisionalmente para decaer de nuevo. En «Los trabajos de la ballena» la población costera no disfrutó de la totalidad del cetáceo, pero en el fondo se unieron fuerzas como parte de la identidad colectiva.

De acuerdo con la Organización de las Naciones Unidas para la Educación, la Ciencia y la Cultura, la cultura es el conjunto de rasgos distintivos que caracterizan a una sociedad (UNESCO). Destacar los modos de obrar del ser humano, con su sistema de valores, tradiciones y creencias es llevar a cabo una identificación completa de la manera de estar en el mundo. Los pueblos latinoamericanos guardan entre sí, coincidencias surgidas de su pasado colonial, concurrencias temáticas expresadas con cualidades distintas, pero unidas en la génesis de un pretérito compartido.

La narrativa permite observar los sentimientos de pertenencia y la presencia de lo residual en la memoria de los actores sociales (Macías Reyes), es así que los tópicos de la identidad colectiva, la creencia comunitaria y las relaciones entre personas de distinto género aparecen. La mutua cooperación entre los individuos que comparten un espacio determinado mediante símbolos comunes para lograr todos o algunos de los fines de la vida, define el término sociedad (Gómez Pellón). La relación de la literatura con la sociedad y su influencia mutua se trabaja desde la representación por escrito de las ideas dominantes de la época de gestación de las obras.

Para finalizar, es pertinente dar a conocer la tabla completa con los doce cuentos considerados en el corpus narrativo, los tópicos no fueron elegidos, como se ha dicho, sino que manaron por sí mismos:

\begin{tabular}{|l|l|l|}
\hline \multicolumn{1}{|c|}{ Cuento } & \multicolumn{1}{|c|}{ Autor } & \multicolumn{1}{c|}{ Procedencia } \\
\hline «Antierótica XXI» & Laura Fuentes Belgrave & Costa Rica, 2013 \\
\hline «Depende» & Guillermo Sheridan & México, 1996 \\
\hline «La fila» & Justo Arroyo & Panamá, 1990 \\
\hline «Y vendimos la lluvia» & Carmen Naranjo & Costa Rica, 1989 \\
\hline «Los trabajos de la ballena» & Eraclio Zepeda & México, 1959 \\
\hline «La vaca» & Carlos Changmarín & Panamá, 1959 \\
\hline "Cosas de tonto» & Saray Amador & Costa Rica, 1996 \\
\hline «Macario» & Juan Rulfo & México, 1953 \\
\hline «El juego» & Pedro Rivera & Panamá, 1969 \\
\hline «La bolsa plástica» & Ailyn Morera & Costa Rica, 2007 \\
«Ciclo» & Queta Navagómez & México, 2010 \\
\hline « Y para cuándo será?» & Moravia Ochoa & Panamá, 2005 \\
\hline
\end{tabular}

Tabla 3. Corpus narrativo Proyecto de investigación «Narrar a tres voces». Elaboración propia.

Como puede observarse, el corpus narrativo corre del año $1953 \mathrm{al}$ año 2013, sesenta ańos de cuento latinoamericano, periodo que permite observar cuatro tópicos predominantes: la burocracia tratada desde la ironía; la identidad colectiva vista desde el humor; la corrupción de la inocencia por parte de mujeres adultas hacia menores de edad y el también abuso sexual por parte de figuras paternas hacia las niñas.

\section{Bibliografía}

Álvarez-MunáRriz, Luis. «La compleja identidad personal", Revista de Dialectología y Tradiciones Populares. LXVI:2, (2011): 407-432, 2011. Recuperado del Instituto de Lengua, Literatura y Antropología (CSIC) el 23 de agosto del 2016: rdtp.revistas.csic.es/index. $\mathrm{php/rdtp/article/viewFile/257/257.}$ 
Beristáin, Helena. Diccionario de retórica y poética. México: Porrúa, 1995.

Chacón, Albino (coord.). Diccionario de la literatura centroamericana. San José: Editorial Costa Rica, 2007.

Changmarín, Carlos. «La vaca». Faragual y otros cuentos. Panamá: Manfer, 1999.

Della Porta, Donatella \& Diani, Mario. Los movimientos sociales. Madrid: Universidad Complutense de Madrid, 2011.

Duchet, Claude. «Para una socio-crítica o variaciones sobre un íncipit». Malcuzynski, M. P. (ed. y coord.). Sociocriticas. Prácticas textuales. Cultura de fronteras. Países Bajos: Editions Rodopi, 1991.

Duchet, Claude. «Posiciones y perspectivas sociocríticas». Malcuzynski, M. P. (ed. y coord.). Sociocriticas. Prácticas textuales. Cultura de fronteras. Países Bajos: Editions Rodopi, 1991.

Guzmán Díaz, José Manuel. Sociocrítica del luto humano. Tesis, Universidad Nacional Autónoma de México, 2003.

Fernández Quirós, Esther \& Hernández Tenorio, Cristina Isabel. «Ensayo sobre Identidades». Hekademos. Revista Educativa Digital, III:6, (2010): 77-96. Recuperado de hekademos.com/hekademos/ content/view/76/32/

Fuentes, Carlos. Los días enmascarados. México: Ediciones Era, 2013.

Giménez, Gilberto. Cultura, Identidad y Procesos de Individualización. México: Universidad Nacional Autónoma de México, 2010.

Gómez Pellón, Eloy. «Introducción a la antropología social y cultural». España: Universidad de Cantabria. Recuperado de ocw.unican.es/pluginfile.php/2203/ mod_resource/content/1/Glosario.pdf.

Maestro, Jesús G. «La literatura comparada según el Materialismo Filosófico como Teoría de la Literatura», Academia Editorial del Hispanismo. Recuperado el 28 de agosto del 2016 de: www.academiaeditorial.com/ web/que-es-la-literatura-comparada/.

Martínez SuÁrez, José Luis. «Presentación». En Villegas, Irlanda \& Reyes, David (coord.). (2014) ¿Qué es la literatura comparada? Impresiones actuales. Veracruz: Universidad Veracruzana, 2014: 7-8.

Mercado Maldonado, Asael \& Hernández Oliva, Alejandrina. «El proceso de construcción de la identidad colectiva", Convergencia. Revista de Ciencias Sociales, (2010): 17-53. Recuperado el miércoles 24 de agosto del 2016 del sitio web SciELO México. Scientific Electronic Library Online: http:// www.scielo.org. $\mathrm{mx} /$ scielo.php?script=sci_arttext\&pi $\mathrm{d}=$ S1405-14352010000200010

Miró, Rodrigo. El cuento en Panamá (Estudio, selección, bibliografia). Panamá: Editorial Universitaria, 1996.

Moliner, María. Diccionario del uso del español. Vol. 1. Madrid: Gredos, 2007.

Nueva Biblia de Jerusalén. Revisada y aumentada. Bilbao, Desclée De Brouwer, 1998.

Naranjo, Carmen. Otro rumbo para la rumba. San José: EDUCA, 1989.

Puga, María Luisa. La ceremonia de iniciación. México: Fondo de Cultura Económica, 1994.

Ramírez, Sergio y González, Jézer (comps.). Antología del relato costarricense (1890-1930; 1930-1970). San José: Editorial de la Universidad de Costa Rica, 2000.

Ramos R., José Luis. «Las identidades étnica y nacional de maestros mixtecos (México), ¿contradictorias o complementarias?», Gazeta de Antropología. España: Universidad de Granada (2010). Recuperado el 24 de agosto del 2016 de: www.ugr.es/ - pwlac/G26_24Jose_ Luis_Ramos.html.

Rivera, Pedro. «Prólogo a Las mentiras encantadas». Cuentos para ser contados. Panamá: Editorial Universitaria, 1997.

Seymour, Menton (comp.). Antología del cuento centroamericano. San José: Educa, 1973.

Valenzuela Arce, José Manuel (coord.). Decadencia y auge de las identidades. Cultura nacional, identidad cultural y modernización. México: Colegio de la Frontera Norte, 2015.

VÁsQuez, Margarita. "El cuento en Panamá (19502001). Abundancia de peces». Contrapunto. Doce ensayos sobre la literatura en Panamá. Panamá: Editorial Universitaria, 2008.

VÁsQuez, Margarita. Diccionario del español en Panamá. Panamá: Editorial Universitaria Carlos Manuel Gasteazoro, 2010.

Viladot Presas, M. Á. Lengua y comunicación intergrupal. Barcelona: Editorial UOC, 2010.

Xamist, F. J. «Contrapunto. Reflexiones en torno a los métodos de la Literatura Comparada", $452^{\circ} \mathrm{F}$. Revista electrónica de teoría de la literatura y literatura comparada, 5 (2011): 32-44. Recuperado el 26 de agosto de 2016 de www.452f.com/ index.php/es/federico-josexamist.html.

Zepeda, Eraclio. Benzulul. Asalto nocturno. Lecturas Mexicanas. México: Consejo Nacional para la Cultura y las Artes, 2004. 